BNL- 113913-2017 -JA

\title{
Translating Thermal Response of Triblock CopolymerAssemblies in Dilute Solution to Macroscopic Gelation and Phase Separation
}

\author{
Zhe Sun, Ye Tian, Wendy L. Hom, \\ Oleg Gang, Surita R. Bhatia, and Robert B. Grubbs
}

Angewandte Chemie International Edition

December 2016

Center for Functional Nanomaterials

Brookhaven National Laboratory

\author{
U.S. Department of Energy \\ USDOE Office of Science (SC), \\ Basic Energy Sciences (SC-22)
}

Notice: This manuscript has been authored by employees of Brookhaven Science Associates, LLC under Contract No. DE- SC0012704 with the U.S. Department of Energy. The publisher by accepting the manuscript for publication acknowledges that the United States Government retains a non-exclusive, paid-up, irrevocable, world-wide license to publish or reproduce the published form of this manuscript, or allow others to do so, for United States Government purposes. 


\section{DISCLAIMER}

This report was prepared as an account of work sponsored by an agency of the United States Government. Neither the United States Government nor any agency thereof, nor any of their employees, nor any of their contractors, subcontractors, or their employees, makes any warranty, express or implied, or assumes any legal liability or responsibility for the accuracy, completeness, or any third party's use or the results of such use of any information, apparatus, product, or process disclosed, or represents that its use would not infringe privately owned rights. Reference herein to any specific commercial product, process, or service by trade name, trademark, manufacturer, or otherwise, does not necessarily constitute or imply its endorsement, recommendation, or favoring by the United States Government or any agency thereof or its contractors or subcontractors. The views and opinions of authors expressed herein do not necessarily state or reflect those of the United States Government or any agency thereof. 


\title{
Translating Thermal Response of Triblock Copolymer Assemblies in Dilute Solution to Macroscopic Gelation and Phase Separation
}

\author{
Zhe Sun, Ye Tian, Wendy L. Hom, Oleg Gang, Surita R. Bhatia, and Robert B. Grubbs*
}

\begin{abstract}
The thermal response of semi-dilute solutions (5 w/ $w \%)$ of two amphiphilic thermoresponsive poly(ethylene oxide)-b-poly( $N, N$-diethylacrylamide)-b-poly $(N, N$-dibutylacrylamide) $\left(\mathrm{PEO}_{45}-\mathrm{PDEAm_{x } - \mathrm { PDBAm }} \mathrm{m}_{12}\right)$ triblock copolymers, which differ only in the size of the central responsive block, in water was examined. Aqueous $P^{2} O_{45}-P D E A m_{41}-P D B A m_{12}$ solutions, which undergo a thermally induced sphere-to-worm transition in dilute solution, were found to reversibly form soft $\left(G^{\prime} \approx 10 \mathrm{~Pa}\right)$ free-standing physical gels after $10 \mathrm{~min}$ at $55^{\circ} \mathrm{C}$. $\mathrm{PEO}_{45}-\mathrm{PDEAm} \mathrm{m}_{89}-\mathrm{PDBAm} \mathrm{m}_{12}$ copolymer solutions, which undergo a thermally induced transition from spheres to large compound micelles (LCM) in dilute solution, underwent phase separation after heating at $55^{\circ} \mathrm{C}$ for 10 min owing to sedimentation of LCMs. The reversibility of LCM formation was investigated as a non-specific method for removal of a watersoluble dye from aqueous solution. The composition and size of the central responsive block in these polymers dictate the microscopic and macroscopic response of the polymer solutions as well as the rates of transition between assemblies.
\end{abstract}

Stimulus-responsive polymers have been exploited in applications including biomedicine, sensing, molecular actuation, and separations. ${ }^{[1]}$ With block copolymers, the introduction of stimuli-responsive blocks ${ }^{[2]}$ can strongly influence block copolymer self-assembly and can allow triggered transformations between different assemblies. ${ }^{[3]}$ The precise morphology adopted by a given block copolymer mainly depends on the relative volume fractions of the hydrophilic and hydrophobic blocks and the interfacial energy associated with the block junction, ${ }^{[3 \mathrm{c}, 4]}$ so if the degree of hydrophilicity of a given block can be altered in response to external stimuli, the morphology

[*] Dr. Z. Sun, W. L. Hom, Prof. S. R. Bhatia, Prof. R. B. Grubbs Department of Chemistry, Stony Brook University

Stony Brook, NY 11764-3400 (USA)

E-mail: robert.grubbs@stonybrook.edu

Dr. Y. Tian, Dr. O. Gang

Center for Functional Nanomaterials

Brookhaven National Laboratory

Upton, NY 11974 (USA)

Dr. O. Gang

Department of Chemical Engineering, Columbia University New York, NY 10027 (USA)

and

Department of Applied Physics and Applied Mathematics

Columbia University

New York, NY 10027 (USA)

(6) Supporting information, including experimental details, and the

iD ORCID identification number(s) for the author(s) of this article can be found under:

http://dx.doi.org/10.1002/anie.201609360. of the polymer aggregates can change significantly. Several examples of thermally responsive polymers that undergo thermally induced morphological transitions between welldefined structures in dilute solution have been reported. ${ }^{[5]}$

For example, poly(ethylene oxide)-block-poly ( $N$-isopropylacrylamide)-block-poly(isoprene) (PEO-PNIPAm-PI) triblock copolymers in dilute aqueous solution with specific compositions form small spherical micelles at low temperatures that reassemble into large vesicles after heating above the lower critical solution temperature (LCST) for three weeks. ${ }^{[5 a]}$ More rapid transitions have been demonstrated with polymers with lower-molecular-weight hydrophilic components. ${ }^{[\mathrm{d}]}$ We have hypothesized that, in addition to molecular weight effects, interchain hydrogen bonding between PNIPAm amide groups after dehydration above the LCST can kinetically trap micelles and slow further rearrangement. As evidence for this hypothesis, poly(ethylene oxide)-block-poly(ethylene oxide-stat-butylene oxide)block-poly(isoprene) (PEO-P(EO/BO)-PI) triblock copolymers were found to undergo a sphere-to-vesicle transition upon heating above the $\mathrm{P}(\mathrm{EO} / \mathrm{BO})$ LCST within several hours. $^{[5 a]}$

To further probe this hypothesis, we have investigated the dilute solution behavior of poly(ethylene oxide)-blockpoly $(N, N$-diethylacrylamide)-block-poly $(N, N$-dibutylacrylamide) (PEO-PDEAm-PDBAm) copolymers synthesized by reversible addition-fragmentation chain transfer (RAFT) polymerization (Scheme 1), ${ }^{[6]}$ in which the stimulus respon-

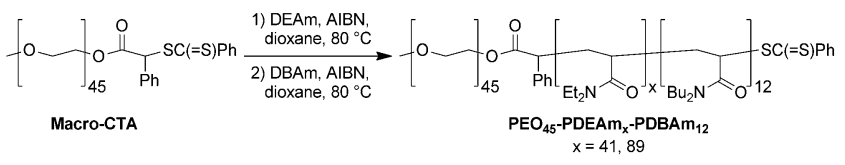

Scheme 1. Synthesis of $\mathrm{PEO}_{45}-\mathrm{PDEAm}_{89}-\mathrm{PDBAm} \mathrm{m}_{12}$ copolymers.

sive block has an LCST in water similar to that of PNIPAm but cannot form strong interchain hydrogen bonds. In the course of these studies, we have identified two copolymers, $\mathrm{PEO}_{45}-\mathrm{PDEAm}_{41}-\mathrm{PDBAm}_{12}\left(M_{\mathrm{n}}=5.2 \mathrm{~kg} \mathrm{~mol}^{-1}\right.$; spherical to worm-like micelle $)$ and $\mathrm{PEO}_{45}-\mathrm{PDEAm}_{89}-\mathrm{PDBAm}_{12}\left(M_{\mathrm{n}}=\right.$ $11.3 \mathrm{~kg} \mathrm{~mol}^{-1}$; spherical to large compound micelle) that undergo rapid transitions from spherical micelles to larger aggregates upon heating (Scheme 1, Table 1). Herein, we describe the solution behavior of these two copolymers in water at higher concentrations ( $\geq 5.0 \mathrm{w} / \mathrm{w} \%$ ) before and after heating above the PDEAm LCST.

Transmission electron microscopy (TEM) and dynamic light scattering (DLS) studies of dilute aqueous $\mathrm{PEO}_{45^{-}}$ 
Table 1: Molecular characteristics of PEO-PDEAm-PDBAm triblock copolymers.

\begin{tabular}{cccccc}
\hline \multicolumn{1}{c}{ Copolymer $^{[\mathrm{a}]}$} & \multicolumn{2}{c}{$\mathrm{M}_{\mathrm{n}}\left[\mathrm{kg} \mathrm{mol}^{-1}\right]^{[\mathrm{a}]}$} & $\bigoplus^{[\mathrm{b}]}$ & \multicolumn{2}{c}{$f_{\text {hydrophilic }}{ }^{[\mathrm{c}]}$} \\
& PDEAm & total & & $25^{\circ} \mathrm{C}$ & $55^{\circ} \mathrm{C}$ \\
\hline PEO $_{45}$-PDEAm $_{41}-$ PDBAm $_{12}$ & 5.2 & 9.4 & 1.29 & 0.75 & 0.20 \\
PEO $_{45}$ PDEAm $_{89}-$ PDBAm $_{12}$ & 11.3 & 15.5 & 1.34 & 0.84 & 0.13 \\
\hline
\end{tabular}

[a] $M_{\mathrm{n}}$ values for PDEAm block and triblock copolymer in $\mathrm{kg} / \mathrm{mol}$ as determined from the polymerization conversions determined by ${ }^{1} \mathrm{H}$ NMR of crude reaction mixtures and the molecular weight of the PEO-CTA. [b] Dispersity ( $(D)$ determined by SEC in THF calibrated with PS standards. [c] Hydrophilic weight fraction calculated by the mass of the hydrophilic block or blocks (PEO and PDEAm at $25^{\circ} \mathrm{C}$; PEO at $55^{\circ} \mathrm{C}$ ) to the total mass of polymer.

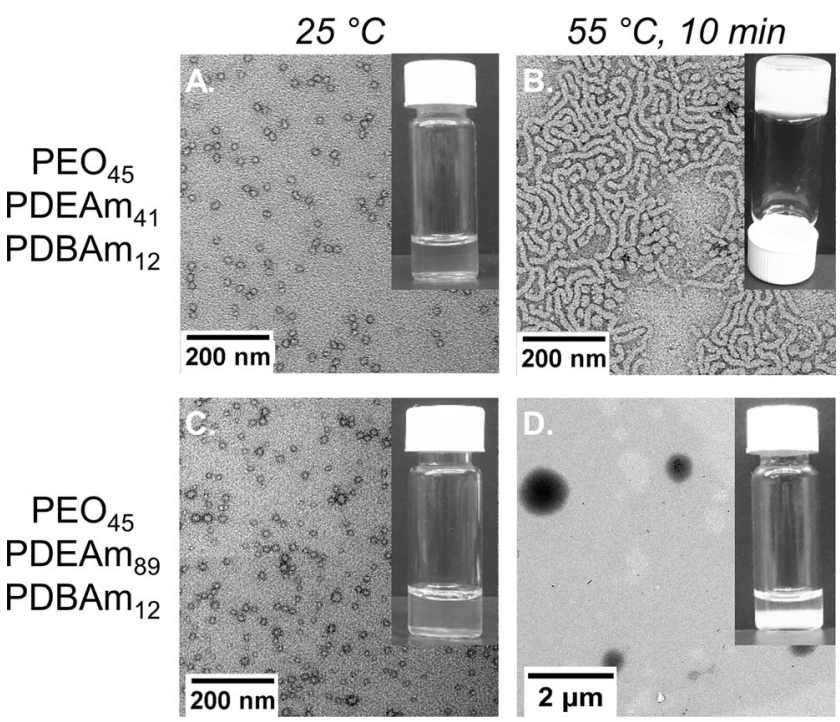

Figure 1. TEM images of $0.1 \mathrm{w} / \mathrm{w} \%$ aqueous solutions of $A, B) P E O_{45}$ PDEAm $_{41}-$ PDBAm $_{12} \mathrm{C}$, D) and PEO $_{45}-$ PDEAm $_{89}-$ PDBAm $_{12}$ at $25^{\circ} \mathrm{C}$ and after heating at $55^{\circ} \mathrm{C}$ for $10 \mathrm{~min}$. Inset images are photographs of vials of $5.0 \mathrm{w} / \mathrm{w} \%$ solutions of the indicated polymers at the given temperature. Scale bar $=200 \mathrm{~nm}(\mathrm{~A}-\mathrm{C})$; Scale bar $=2 \mu \mathrm{m}$ (D). Color image available in the Supporting Information.

PDEAm $_{\mathrm{x}}-\mathrm{PDBAm}_{12}$ solutions $(0.10 \mathrm{w} / \mathrm{w} \%$; Figure $1 \mathrm{~A}, \mathrm{C}$ and the Supporting Information, Figure S3) confirmed that both triblock copolymers form spherical micelles in water at $25^{\circ} \mathrm{C}$ owing to their large hydrophilic weight fractions $(f \geq 0.75) .^{[7]}$ DLS data suggest that $\mathrm{PEO}_{45}-\mathrm{PDEAm}_{89}-\mathrm{PDBAm}_{12}$ appears to assemble into slightly larger micelles $\left(D_{\mathrm{h}}=26 \mathrm{~nm}\right)$ than $\mathrm{PEO}_{45}-\mathrm{PDEAm}_{41}-\mathrm{PDBAm}_{12}\left(D_{\mathrm{h}}=24 \mathrm{~nm}\right)$, most likely resulting from the significantly larger central corona block in $\mathrm{PEO}_{45}-\mathrm{PDEAm}_{89}-\mathrm{PDBAm}_{12}$ (Supporting Information, Figure $\mathrm{S} 3 \mathrm{c}$ ).

Heating dilute solutions of both polymers $\left(0.2^{\circ} \mathrm{Cmin}^{-1}\right.$; Supporting Information, Figure S4) resulted in significant increases in apparent $D_{\mathrm{h}}$ (DLS) above the LCST of the PDEAm blocks (LCST $\approx 41^{\circ} \mathrm{C}$ for $M_{\mathrm{n}}=4.7 \mathrm{~kg} \mathrm{~mol}^{-1}$; LCST $\approx 33^{\circ} \mathrm{C}$ for $\left.M_{\mathrm{n}}=9.6 \mathrm{~kg} \mathrm{~mol}^{-1}\right) \cdot .^{[8]}$ For $\mathrm{PEO}_{45^{-}} \mathrm{PDEAm}_{41^{-}}$ PDBAm $_{12}, D_{\mathrm{h}}$ began to increase near $45^{\circ} \mathrm{C}$ from $24 \mathrm{~nm}$ to greater than $150 \mathrm{~nm}$, while for $\mathrm{PEO}_{45}-\mathrm{PDEAm}_{89}-\mathrm{PDBAm}_{12}$, $D_{\mathrm{h}}$ increased near $35^{\circ} \mathrm{C}$ from $26 \mathrm{~nm}$ to almost $300 \mathrm{~nm}$. For both polymer solutions, the changes in apparent $D_{\mathrm{h}}$ were reversible over two heating/cooling cycles (Supporting Information, Figure S5).

TEM images of $\mathrm{PEO}_{45}-\mathrm{PDEAm}_{41}-\mathrm{PDBAm}_{12}$ samples prepared from $0.1 \mathrm{w} / \mathrm{w} \%$ solutions after heating at $55^{\circ} \mathrm{C}$ for 10 min (Figure 1B), showed the spherical micelles had grown into worm-like micelles. TEM images of $\mathrm{PEO}_{45}-\mathrm{PDEAm}_{89^{-}}$ PDBAm $_{12}$ solutions $(0.1 \mathrm{w} / \mathrm{w} \%)$ showed the formation of large polydisperse spheres without any bilayer contrast after heating at $55^{\circ} \mathrm{C}$ for $10 \mathrm{~min}$ (Figure $1 \mathrm{D}$ ). These spheres resemble the large compound micelles (LCMs) reported previously for amphiphilic block copolymers with very large hydrophobic blocks. ${ }^{[9]}$ The fast transformation rate from spheres to worms or spheres to LCMs for $\mathrm{PEO}_{45}-\mathrm{PDEAm}_{89^{-}}$ PDBAm $_{12}$ block copolymers (ca. $10 \mathrm{~min}$ ) supports the hypothesis that the absence of strong interchain hydrogen bonding in the thermally responsive block accelerates rearrangement of polymer assemblies.

Amphiphiles with worm-like micelle morphologies can form gels at higher concentrations, even in the absence of specific inter-worm interactions. ${ }^{[5,, 10]}$ Gelation in these cases has been attributed to topological interactions and requires that worms be sufficiently long and stiff to persist over the time scales probed by rheology. ${ }^{[10 c]}$ The behavior of aqueous solutions of $\mathrm{PEO}_{45}-\mathrm{PDEAm}_{41}-\mathrm{PDBAm}_{12}$ at higher concentrations $(5-10 \mathrm{w} / \mathrm{w} \%)$ was investigated to determine if the thermally induced sphere-to-worm transition could result in gelation. A transparent aqueous solution of $\mathrm{PEO}_{45^{-}}$ $\operatorname{PDEAm}_{41}-\mathrm{PDBAm}_{12}(5.0 \mathrm{w} / \mathrm{w} \%)$ was heated at $55^{\circ} \mathrm{C}$. After 10 min the solution formed a soft free-standing physical gel (Figure 1B). Visible degelation occurred within 30-40 s after the sample was removed from the heating bath (Supporting Information, Video S1). Repeated heating and cooling experiments indicated that the gelation is completely thermoreversible. In contrast, phase separation was observed in the $\mathrm{PEO}_{45}-\mathrm{PDEAm}_{89}-\mathrm{PDBAm}_{12}$ aqueous solutions $(5.0 \mathrm{w} / \mathrm{w}$ $\%$ ) after heating at $55^{\circ} \mathrm{C}$ for $10 \mathrm{~min}$, as the concentrated large compound micelles settled to the bottom of the solution (Figure 1D).

Oscillatory temperature sweep experiments (Figure 2) confirm gelation; the storage modulus $\left(G^{\prime}\right)$ of $5.0 \mathrm{w} / \mathrm{w} \%$

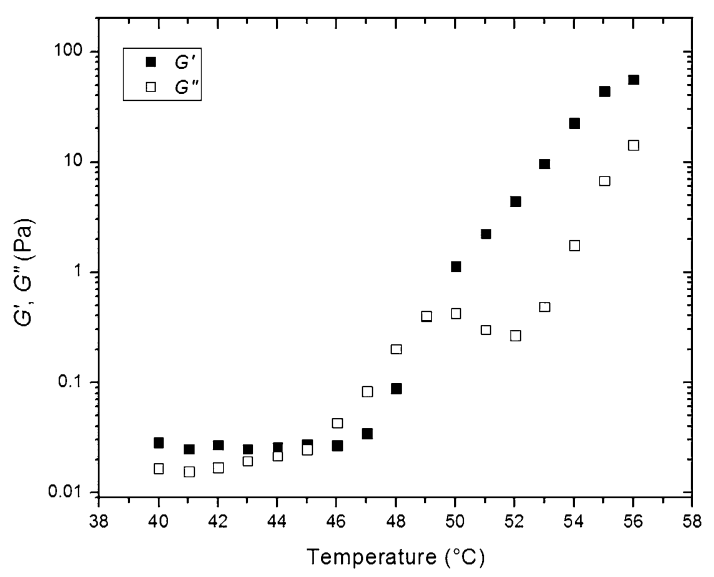

Figure 2. Temperature sweep from $40^{\circ} \mathrm{C}$ to $55^{\circ} \mathrm{C}$ of $5.0 \mathrm{w} / \mathrm{w} \% \mathrm{PEO}_{45^{-}}$ PDEAm $_{41}-$ PDBAm $_{12}$ solutions/gels for $G^{\prime}$ (filled squares) and $G^{\prime \prime}$ (open squares) at a fixed frequency of $1.0 \mathrm{~Hz}$ and $5.0 \%$ strain. 
aqueous $\mathrm{PEO}_{45}-\mathrm{PDEAm}_{41}-\mathrm{PDBAm}{ }_{12}$ triblock copolymer solutions begins to exceed the loss modulus $\left(G^{\prime \prime}\right)$ at $49^{\circ} \mathrm{C},{ }^{[10 a]}$ which agrees well with the temperature $\left(45^{\circ} \mathrm{C}\right)$ at which the onset of assembly growth is observed in dilute solutions. Frequency sweeps at $55^{\circ} \mathrm{C}$ clearly show a characteristic gellike response, with $G^{\prime}$ relatively independent of frequency and greater than $G^{\prime \prime}$ over the entire range of measured frequencies (Supporting Information, Figure S6). ${ }^{[10 a, 11]}$ This can be contrasted with the results from frequency sweeps taken at $25^{\circ} \mathrm{C}$ and $45^{\circ} \mathrm{C}$ (Supporting Information, Figure S6), in which both $G^{\prime}$ and $G^{\prime \prime}$ show a frequency-dependence characteristic of a viscoelastic liquid. The gel phase is fairly soft, with $G^{\prime}$ increasing from $10-100 \mathrm{~Pa}$ as the polymer concentration was raised from 5.0 to $10.0 \mathrm{w} / \mathrm{w} \%$ (Supporting Information, Figure S7).

The small dip in the value of $G^{\prime \prime}$ that can be seen in the temperature sweeps immediately after the gel transition (49$52^{\circ} \mathrm{C}$ ) (Figure 2) is somewhat curious. This feature appears reproducibly in temperature sweeps of various samples at different concentrations (Supporting Information, Figure S7), and likely results from two competing phenomena: 1) The growth of worm-like micelles resulting from the thermally induced change in polymer amphiphilicity, and 2) the decrease in worm-like micelle length and relaxation time that has been seen in surfactant-based worm-like micelles with increasing temperature. ${ }^{[10 c]}$ As the temperature increases, this competition would lead to a complex dependence of the moduli on temperature near the gel transition. Eventually the increasing length of the micelles dominates, and gel formation is favored.

Potential applications of large compound micelles have not been widely explored. The presence of hydrophilic domains within a large excluded phase suggests that the reversible formation of large compound micelles could be of use in the encapsulation and concentration of water-soluble contaminants in water. The encapsulating ability of the large compound micelles formed by $\mathrm{PEO}_{45}-\mathrm{PDEAm}_{89}-\mathrm{PDBAm}_{12}$ was investigated by dye-encapsulation experiments using the hydrophilic dye rhodamine B (Supporting Information, Table S1). An aqueous solution of $\mathrm{PEO}_{45} \mathrm{PDEAm}_{89^{-}}$ PDBAm $_{12}(5.0 \mathrm{w} / \mathrm{w} \%)$ and rhodamine B (ca. $\left.2 \mathrm{ppm}\right)$ was heated at $55^{\circ} \mathrm{C}$ to induce phase separation and the top aqueous layer (ca. $0.4 \mathrm{ppm}$ rhodamine B) was removed. A small amount of water at a temperature of $55^{\circ} \mathrm{C}$ that was added atop the bottom polymer-rich layer remained clear after 10 min at $55^{\circ} \mathrm{C}$ with minimal extraction of rhodamine $\mathrm{B}$ (ca. $0.08 \mathrm{ppm}$ ) from the polymer phase (Supporting Information, Figure S8), indicating that rhodamine B was encapsulated inside the large compound micelles. Cooling the bottom layer down to $25^{\circ} \mathrm{C}$ resulted in reformation of a transparent micelle solution enriched with rhodamine B (ca. 2.7 ppm; Supporting Information, Figure S9).

In summary, two members of a new class of thermally responsive ABC PEO-PDEAm-PDBAm triblock copolymers synthesized by RAFT polymerization show macroscopic behavior in semidilute solution that reflects the microscopic changes observed in dilute solution; copolymers that undergo a spherical-to-cylindrical micelle transition in dilute solution form gels at higher concentrations, while copolymers that undergo a spherical-to-large-compound micelle transition in dilute solution undergo phase separation at higher concentrations. The fast heating-induced growth rates (within $10 \mathrm{~min}$ ), even faster transitions back to spherical micelles upon cooling (within $1 \mathrm{~min}$ ), and reversibility of the transformations support our hypothesis that the absence of strong interchain hydrogen bonding in the central thermally responsive block facilitates rapid growth of smaller aggregates into larger ones at the macroscopic as well as the microscopic level. Further manipulation of block copolymer composition and monomer functionality should allow the development of control over gelation temperature and rate, as well as the ability of large compound micelles to encapsulate hydrophilic compounds.

\section{Acknowledgements}

This research was supported by the National Science Foundation (R.B.G.: DMR-1105622; S.R.B.: CBET-1335787) and was partially carried out at the Center for Functional Nanomaterials, a U.S. DOE Office of Science Facility, at Brookhaven National Laboratory under Contract No. DESC0012704.

\section{Conflict of interest}

The authors declare no conflict of interest.

Keywords: block copolymers - gels - micelles - nanostructures . self-assembly

How to cite: Angew. Chem. Int. Ed. 2017, 56, 1491-1494 Angew. Chem. 2017, 129, 1513-1516

[1] a) M. A. Stuart, W. T. Huck, J. Genzer, M. Muller, C. Ober, M. Stamm, G. B. Sukhorukov, I. Szleifer, V. V. Tsukruk, M. Urban, F. Winnik, S. Zauscher, I. Luzinov, S. Minko, Nat. Mater. 2010, 9 , $101-113$; b) M. I. Gibson, R. K. O'Reilly, Chem. Soc. Rev. 2013, 42, 7204-7213; c) D. Roy, W. L. Brooks, B. S. Sumerlin, Chem. Soc. Rev. 2013, 42, 7214-7243; d) E. G. Kelley, J. N. L. Albert, M. O. Sullivan, T. H. Epps, Chem. Soc. Rev. 2013, 42, 7057-7071; e) M. Karimi, A. Ghasemi, P. Sahandi Zangabad, R. Rahighi, S. M. Moosavi Basri, H. Mirshekari, M. Amiri, Z. Shafaei Pishabad, A. Aslani, M. Bozorgomid, D. Ghosh, A. Beyzavi, A. Vaseghi, A. R. Aref, L. Haghani, S. Bahrami, M. R. Hamblin, Chem. Soc. Rev. 2016, 45, 1457-1501; f) L. Sambe, V. R. de La Rosa, K. Belal, F. Stoffelbach, J. Lyskawa, F. Delattre, M. Bria, G. Cooke, R. Hoogenboom, P. Woisel, Angew. Chem. Int. Ed. 2014, 53, 5044-5048; Angew. Chem. 2014, 126, $5144-$ $5148 ;$ g) A. Yamada, Y. Hiruta, J. Wang, E. Ayano, H. Kanazawa, Biomacromolecules 2015, 16, 2356-2362; h) S. Uchiyama, N. Kawai, A. P. de Silva, K. Iwai, J. Am. Chem. Soc. 2004, 126, 3032-3033; i) C. Li, N. Gunari, K. Fischer, A. Janshoff, M. Schmidt, Angew. Chem. Int. Ed. 2004, 43, 1101-1104; Angew. Chem. 2004, 116, 1121-1124.

[2] R. B. Grubbs, Z. Sun, Chem. Soc. Rev. 2013, 42, 7436-7445.

[3] a) Y. Mai, A. Eisenberg, Chem. Soc. Rev. 2012, 41, 5969-5985; b) T. H. Epps III, R. K. O'Reilly, Chem. Sci. 2016, 7, 1674-1689; c) A. Blanazs, S. P. Armes, A. J. Ryan, Macromol. Rapid Commun. 2009, 30, 267-277. 
[4] J. N. Israelachvili, Intermolecular and Surface Forces, $3^{\text {rd }}$ Ed. Academic Press: Burlington, Massachusetts, 2011

[5] a) A. Sundararaman, T. Stephan, R. B. Grubbs, J. Am. Chem. Soc. 2008, 130, 12264-12265; b) D. Roy, J. N. Cambre, B. S Sumerlin, Chem. Commun. 2009, $2106-2108$; c) J. P. Zhao, G. Z. Zhang, S. Pispas, J. Polym. Sci. Part A 2009, 47, 4099-4110; d) A. O. Moughton, R. K. O'Reilly, Chem. Commun. 2010, 46, 1091-1093; e) A. E. Smith, X. Xu, S. E. Kirkland-York, D. A. Savin, C. L. McCormick, Macromolecules 2010, 43, 1210-1217; f) Y. Cai, K. B. Aubrecht, R. B. Grubbs, J. Am. Chem. Soc. 2011, 133, 1058-1065; g) A. Blanazs, R. Verber, O. O. Mykhaylyk, A. J. Ryan, J. Z. Heath, C. W. Douglas, S. P. Armes, J. Am. Chem. Soc. 2012, 134, 9741 -9748; h) J. Y. Quek, Y. C. Zhu, P. J. Roth, T. P. Davis, A. B. Lowe, Macromolecules 2013, 46, 7290-7302; i) R. Banerjee, D. Dhara, Langmuir 2014, 30, 4137-4146 j) M. H. Dan, F. Huo, X. Xiao, Y. Su, W. Q. Zhang, Macromolecules 2014, 47, 1360-1370; k) K. Wei, L. Su, G. Chen, M. Jiang, Polymer 2011, 52, 3647-3654.

[6] a) A. Walther, P. E. Millard, A. S. Goldmann, T. M. Lovestead, F. Schacher, C. Barner-Kowollik, A. H. E. Muller, Macromolecules 2008, 41，8608-8619; b) Y. T. Li, B. S. Lokitz, C. L. McCormick, Macromolecules 2006, 39, 81-89.
[7] D. E. Discher, F. Ahmed, Annu. Rev. Biomed. Eng. 2006, 8, $323-$ 341.

[8] a) R. Freitag, T. Baltes, M. Eggert, J. Polym. Sci. Part A 1994, 32, 3019-3030; b) D. G. Lessard, M. Ousalem, X. X. Zhu, A. Eisenberg, P. J. Carreau, J. Polym. Sci. Part B 2003, 41, $1627-$ 1637.

[9] a) L. Zhang, A. Eisenberg, Science 1995, 268, 1728-1731; b) L. F. Zhang, A. Eisenberg, J. Am. Chem. Soc. 1996, 118, 3168-3181; c) N. J. Warren, O. O. Mykhaylyk, A. J. Ryan, M. Williams, T. Doussineau, P. Dugourd, R. Antoine, G. Portale, S. P. Armes, J. Am. Chem. Soc. 2015, 137, 1929-1937.

[10] a) Z. Chu, C. A. Dreiss, Y. Feng, Chem. Soc. Rev. 2013, 42, 71747203; b) R. Kumar, G. C. Kalur, L. Ziserman, D. Danino, S. R. Raghavan, Langmuir 2007, 23, 12849-12856; c) S. R. Raghavan, J. F. Douglas, Soft Matter 2012, 8, 8539-8546.

[11] S. K. Ahn, R. M. Kasi, S. C. Kim, N. Sharma, Y. X. Zhou, Soft Matter 2008, 4, 1151-1157. 